\title{
Psychosocial impact of visual impairment in working-age adults
}

\author{
S R Nyman, ${ }^{1}$ M A Gosney, ${ }^{1,2}$ C R Victor ${ }^{1}$
}

- Additional tables are published online only. To view these files please visit the journal online (http://bjo.bmj. com).

${ }^{1}$ Clinical Health Sciences, University of Reading, Reading, UK

${ }^{2}$ Elderly Care Medicine, Royal Berkshire NHS Foundation Trust, Reading, UK

\section{Correspondence to}

Dr Samuel R Nyman, School of Design, Engineering \&

Computing, Bournemouth

University, Poole House, Talbot Campus, Poole, Dorset BH12

5BB, UK;

snyman@bournemouth.ac.uk

Accepted 30 September 2009 Published Online First

22 October 2009

\section{ABSTRACT}

Aim To review the evidence for the presence of lower levels of psychosocial well-being in working-age adults with visual impairment and for interventions to improve such levels of psychosocial well-being.

Methods Systematic review of quantitative studies published in English from 2001 to July 2008 that measured depression/mental health, anxiety, quality of life, social functioning or social support.

Results Included were 29 studies that measured one or more outcomes $(\mathrm{N}=52)$. Working-age adults with visual impairment were significantly more likely to report lower levels of mental health (mean difference $=14.51 / 100$ ), social functioning $(\mathrm{MD}=11.55 / 100)$ and quality of life. Studies regarding the prevalence of depressive symptoms produced inconsistent results but had methodological limitations.

Conclusions Future research is required into the prevalence of loneliness, anxiety and depression in adults with visual impairment, and to evaluate the effectiveness of interventions for improving psychosocial well-being such as counselling, peer support and employment programmes.

It is estimated that 80000 adults in the UK aged 18-64 (16-64 in Scotland) have a visual acuity of $<6 / 18$, which represents $8.16 \%$ of those eligible for registration as blind or partially sighted. ${ }^{1}$ Older people are the clear majority of the population with visual impairment, and macular degeneration is the major cause of blindness in Europe and developed countries. ${ }^{2}$ However, working-age adults live with visual impairment longer; their ability to remain socially included, contribute to the workforce and perform care giving roles may be compromised; and they experience different visual impairments to older people with diabetic retinopathy as the major cause of blindness. ${ }^{3}{ }^{4}$ Consequently, working-age adults may present specific needs that require investigation, especially as visual impairment may pose a greater risk to mental health in working-age adults than older people. ${ }^{5}$

Reviews on the psychosocial impact of visual impairment in older people ${ }^{6-17}$ demonstrate an elevated risk of depression and reduced mental health, quality of life and social functioning compared to sighted peers (Nyman, Gosney, Victor, submitted for publication). Social support and psychosocial interventions also show promise for buffering against the negative psychosocial impact of visual impairment (Nyman, Gosney, Victor, submitted for publication). However, there is no review of working-age adults, and this paper presents a review of the psychosocial impact of visual impairment in working-age adults and the effectiveness of rehabilitation or psychosocial interventions in alleviating negative psychosocial consequences.

\section{METHODS}

We electronically searched PsycINFO and Medline for quantitative studies published in English from 2001 to July 2008, which provided data on the psychosocial impact of visual impairment. Inclusion criteria were recruitment of working-age adults (mean age or at least $66 \%$ aged $18-59$ years), had visual impairment or were part of the supportive network (eg, spouse of someone with visual impairment), and provided statistical data on one or more of seven psychosocial outcome measures: depression/mental health, anxiety, quality of life, social functioning, social support, loneliness or the experience of complex visual hallucinations. Studies were excluded if only the abstract was published and if they recruited participants with a significant comorbidity (eg, hearing loss, brain injury, cancer). Although physical functioning such as the ability to independently carry out tasks of daily living is related to psychosocial well-being, studies that only reported physical functioning outcomes or fused them with psychosocial outcomes were excluded.

We used previous search terms selected from the thesaurus of keywords for the databases (see table 1) $)^{8}$ and retrieved 5393 abstracts (339 Medline, 5054 PsycINFO). Further papers were identified from reference lists and previous literature reviews. Review of the abstracts identified 42 papers that met the inclusion criteria, of which 13 were excluded because they either only recruited participants with correctable visual impairment ${ }^{18-29}$ or only provided data on scale development. ${ }^{30}$ For the included papers, study quality was analysed using a modified Downs and Black's score, ${ }^{31}$ where total scores could range from 0 to 18 for observational studies and from 0 to 25 for experimental studies, with better quality reflected in higher scores.

\section{RESULTS}

Twenty-nine studies were reviewed, of which 11 measured one outcome variable and 18 measured either two $(n=16)$ or three $(n=2)$, resulting in 52 separate outcomes for analysis (see table 2 ). Three studies measured both depression and mental health, ${ }^{32-34}$ which were only included once in the following analyses $(n=49)$. The context for the outcomes analysed were that 27842 participants were recruited; mainly from the USA $(n=32)$, with the remaining from Canada $(n=3)$, the UK $(n=2)$ and 12 other countries. Most of the outcomes were 
Table 1 Search strategy for the literature review

\begin{tabular}{|c|c|c|}
\hline \multirow[b]{2}{*}{ Topics } & \multicolumn{2}{|l|}{ Search terms used } \\
\hline & PsycINFO & Medline \\
\hline Visual impairment & $\begin{array}{l}\text { Vision-disorders } \\
\text { Blind } \\
\text { Visual-acuity }\end{array}$ & $\begin{array}{l}\text { Blindness } \\
\text { Visual-acuity } \\
\text { Visually-impaired-persons } \\
\text { Eye-diseases }\end{array}$ \\
\hline Emotional adjustment & $\begin{array}{l}\text { Depression-emotion } \\
\text { Emotional-adjustment } \\
\text { Emotional-responses } \\
\text { Emotional-states } \\
\text { Life-satisfaction } \\
\text { Major-depression } \\
\text { Mental-disorders } \\
\text { Mental-health } \\
\text { Self-esteem } \\
\text { Well-being }\end{array}$ & $\begin{array}{l}\text { Adaptation-psychological } \\
\text { Mental-disorders } \\
\text { Stress, psychological } \\
\text { Depression } \\
\text { Emotions } \\
\text { Mental-health }\end{array}$ \\
\hline Social relations & $\begin{array}{l}\text { Adjustment-disorders } \\
\text { Assistance-social-behaviour } \\
\text { Family-relations } \\
\text { Friendship } \\
\text { Interpersonal-communication } \\
\text { Interpersonal-interaction } \\
\text { Loneliness } \\
\text { Psychosocial-development } \\
\text { Psychosocial-readjustment } \\
\text { Psychosocial-rehabilitation } \\
\text { Social-adjustment } \\
\text { Social-anxiety } \\
\text { Social-behaviour } \\
\text { Social-comparison } \\
\text { Social-environments } \\
\text { Social-integration } \\
\text { Social-interaction } \\
\text { Social-isolation } \\
\text { Social-networks } \\
\text { Social-skills-training } \\
\text { Social-skills } \\
\text { Social-support-networks }\end{array}$ & $\begin{array}{l}\text { Social-adjustment } \\
\text { Social-behaviour } \\
\text { Social-environment } \\
\text { Social-isolation } \\
\text { Social-support }\end{array}$ \\
\hline
\end{tabular}

Reprinted with permission from Burmedi D, Becker S, Heyl V, et al. Emotional and social consequences of age-related low vision. Vis Impair Res 2002;4:50. Copyright $\odot 2002$ Taylor \& Francis Group (http://www.informaworld.com).

from observational $(n=46)$ and cross-sectional $(n=45)$ data. The mean quality score of the observational studies was 13.11 of 18 and ranged from 9 to $16 / 18$. The remaining studies were trials $(n=3)$, each rated with a quality score of $14 / 25$, of which two were randomised controlled trials. Measures of effect size against a control group including ORs are reported, and where these values were not reported, mean differences (MDs) between groups on mean scores or percentage points $(-/+\%)$ are

Table 2 Categorisation and number of outcome measures reviewed

\begin{tabular}{lr}
\hline Outcome variable & $\mathbf{n}^{*}$ \\
\hline Depression/mental health $\dagger$ & 20 \\
Anxiety & 8 \\
Quality of life & 3 \\
Social functioning & 13 \\
Social support & 5 \\
Interventions & 3 \\
Total & 52 \\
\hline
\end{tabular}

*Total number of outcomes for analysis from the 29 papers.

†Three studies measured both depression $(n=9)$ and mental health $(n=11)$. provided with an indication of the total points on the scale (eg, $M=70.65 / 100$ denotes the average mean score on a scale ranging from 0 to 100). Tables 3-8 are available online as a supplementary file at http://bjo.bmj.com.

\section{Depression and mental health}

Twenty studies investigated depression $(n=9)$ and mental health $(n=11)$ in working-age adults with visual impairment (see supplementary table 3).

\section{Depression}

Nine studies screened for symptoms of depression using a range of validated scales, but no study used a clinical diagnosis of depression. Four studies found either no significant or a minimal relationship between visual impairment and depressive symptoms. ${ }^{33-36}$ However, there were studies suggesting a relationship ( $\mathrm{MD}$ on the Hamilton Depression Rating Scale= $+7.78 \%$ and $\mathrm{MD}$ on the Montogomery-Asberg Depression Rating Scale $=+13.13 \%),{ }^{37}$ with depressive symptoms associated with worse diabetic retinopathy in African-Americans with type 1 diabetes $\left(\mathrm{OR}=3.41, \mathrm{R}^{2}=0.06\right)^{38}$ and poorer visual functioning $(\mathrm{MD}=12.8 / 100, \mathrm{r}=0.33)$, but not visual status. ${ }^{32}{ }^{39}$ In addition, a study investigated the influence of changes in "world views"; beliefs about susceptibility to harm from events beyond one's control. ${ }^{40}$ Compared to those with a negative change, those with a positive change in world views reported fewer depressive symptoms. ${ }^{41}$

\section{Mental health}

Ten of 11 studies measured mental health with a version of the National Eye Institute-Visual Function Questionnaire (NEIVFQ), and those with visual impairment $(M=70.65 / 100$, range $=48.85-90.00 / 100),{ }^{32} 34 \quad 42-45$ reported modestly lower scores than controls (average $\mathrm{MD}=14.51 / 100$, range $=0.62-35.00 / 100) .{ }^{34} 4244-47$ Those with poorer vision reported poorer mental health (average $\mathrm{MD}=15.03 / 100$, range $M D=9.88-19.6 / 100),{ }^{34} 4447$ and those who reported depressive symptoms reported poorer mental health $(\mathrm{MD}=9.5 / 100$ and 23.1/100). ${ }^{43} 48$ The Short-Form survey was less sensitive than the NEI-VFO in detecting lower mental health in individuals with visual impairment compared to a control group (36-item Short-Form $M D=3 / 100$ vs NEI-VFO $M D=35 / 100) .{ }^{45}$

\section{Anxiety}

Eight studies investigated anxiety (see supplementary table 4). Worry about blindness has been identified in half of a group of patients with glaucoma, but this decreased to $25 \%$ at 12 months. ${ }^{49}$ Reduced visual functioning but not vision status was associated with anxiety in another study. ${ }^{39}$ However, anxiety was often only elevated to a minimal degree or not at all in individuals with visual impairment. ${ }^{33} 35$ Indeed, in patients with glaucoma, there was no elevation in levels of anxiety when measured either by a clinical diagnosis or on a validated scale for symptoms. $^{37}$

\section{Quality of life}

Three papers investigated quality of life (see supplementary table 5). Across a range of measures, lower scores of quality of life were found in those with visual impairment, ${ }^{50}$ such as those with bilateral visual impairment being four times more likely to report "not feeling full of life" $(\mathrm{OR}=4.63,+9.47 \%) .{ }^{51}$ Life satisfaction was higher in those with positive versus negative changes in views towards the world and themselves (selfesteem). ${ }^{41}$ 


\section{Social functioning}

Thirteen studies investigated social functioning (see supplementary table 6). Nine studies that used the NEI-VFQ found those with visual impairment reported an average mean score of 81.68/100 (51-96/100), which was modestly but significantly lower than controls (average $\mathrm{MD}=10.32 / 100$, range $\left.=0.45-26.40 / 100, \mathrm{R}^{2}=0.29-0.30\right),{ }^{32} \quad 34 \quad 42 \quad 43 \quad 45-47$ and those reporting depressive symptoms had worse scores $(\mathrm{MD}=7.2 / 100$ to $15.5 / 100) .{ }^{32}{ }^{43}$ For the four remaining studies, a range of scales were used that found either non-significant or minimal differences in social functioning within groups or when compared to controls. 36485052

\section{Social support}

Five studies investigated social support (see supplementary table 7). Studies found only minimal differences in reports of receipt of social support as a function of vision status and employment status in those with visual impairment. ${ }^{53-55}$ Depressive symptoms were significantly inversely predicted by perceived social support from family $(\beta=-0.19)$ and friends $(\beta=-0.23) \quad\left(R^{2}=0.12\right)$, and positively predicted by perceived overprotection $(\beta=0.31)\left(R^{2}=0.08\right)$. Although anxiety was not significantly predicted by perceived social support from family and friends, it was positively predicted by perceived overprotection $(\beta=0.21)\left(R^{2}=0.04\right) .{ }^{56}$ Finally, those with retinitis pigmentosa reported significantly worse perceptions of understanding from healthcare staff $(\mathrm{MD}=15) .{ }^{52}$

\section{Psychosocial outcomes of interventions}

Three studies investigated psychosocial outcomes of rehabilitation and interventions (see supplementary table 8). Rehabilitation has potential for meeting emotional support needs, although this may not always be provided. ${ }^{57}$ Rehabilitation can also focus life goals on relationships, which are associated with greater satisfaction with life $(r=0.21)$ and lower levels of depressive symptoms $(r=-0.27) .{ }^{58}$ A study observed that those with visual impairment in extended-employment programmes reported greater satisfaction $(\mathrm{MD}=+47.33 \%)$ and empowerment/independence $(\mathrm{MD}=+49.33 \%)$ if they were registered with the programme for $\geq 8$ years compared to those registered for fewer years. ${ }^{59}$ Further research is required to explain this observation and to test whether any short-term increases in quality of life can be observed.

\section{DISCUSSION}

We reviewed quantitative studies published in English from 2001 to 2008 that investigated the psychosocial impact of visual impairment in working-age adults, and the effectiveness of rehabilitation or psychosocial interventions to alleviate this impact. We included 29 studies that measured one of six outcomes $(\mathrm{N}=52)$. Working-age adults with visual impairment are likely to report a modest reduction in mental well-being and social functioning, and a reduction in quality of life. Visual impairment was not consistently linked with an increase in depressive symptoms and did not predict a reduction in perceived social support, but low levels of perceived social support predicted depressive symptoms and high levels of perceived overprotection predicted symptoms of depression and anxiety.

Our findings are broadly similar to those of older people with visual impairment, but for this group the link between visual impairment and risk of depression is more robust (Nyman, Gosney, Victor, submitted for publication). Surprisingly, depressive symptoms were not linked with visual impairment in four of nine studies with working-age adults. However, this may be an artefact reflecting issues in study design. One study used an insensitive measure (a single item from the Short-Form survey) ${ }^{34}$ and three studies used samples that may have been particularly less likely to report depressive symptoms given that they could either read written text or Braille, ${ }^{35}$ were newly diagnosed with glaucoma and therefore may not have had time to become depressed, ${ }^{36}$ or were recruited into the control arm of an randomised controlled trial that may have inspired hope in treatment to restore vision. ${ }^{33}$ Similar to research with older people, (Nyman, Gosney, Victor, submitted for publication) few studies have evaluated interventions to improve psychosocial well-being in working-age adults with visual impairment, including the potential for employment programmes to improve quality of life.

\section{Challenges}

The studies reviewed were limited in that most were crosssectional observations and so cannot inform of causal relationships or about the longitudinal natural history of psychosocial well-being. Most studies did not recruit matched control groups for comparison but used previously published normative data that may be confounded by differences in demographic characteristics and the environment and method in which the samples were recruited. In addition, as we included studies that recruited adults aged 60 and above as a small proportion of their sample, the prevalence of low psychosocial well-being in working-age adults may be inflated by potentially lower well-being in older people. There was heterogeneity in the measures used, limiting comparisons between studies, and validated scales were not always used and so the use of insensitive measures may explain why some studies did not find significant relationships.

\section{Future research}

There was heterogeneity in how visual impairment was defined, which complicates our synthesis of previous findings. Uniformity in defining blindness $(<3 / 60$ in the better eye with correction) and low vision $(<6 / 18)$ in accordance with the World Health Organization ${ }^{60}$ would facilitate the interpretation of different studies and be conducive for future meta-analyses in this area. Further research is required to clarify if depression and anxiety are more prevalent in working-age adults with visual impairment, with the use of both clinical diagnoses and validated screening tools for symptoms. For this, reduced visual functioning rather than visual impairment per se may well be more predictive of increased levels of depression and anxiety, as suggested by a study on anxiety in this review ${ }^{39}$ and research with older people (Nyman, Gosney, Victor, submitted for publication). Future research on mental health and social functioning are likely to find vision-specific measures such as the NEI-VFQ much more sensitive than generic measures of quality of life such as the Short-Form survey, as indicated by a study on mental health in this review ${ }^{45}$ and research with older people (Nyman, Gosney, Victor, submitted for publication).

Research could also explore whether working-age adults report higher levels of perceived social support than older people, using measures of perceived adequacy of social support from family and friends as measured with older people. ${ }^{61}$ The prevalence of loneliness in working-age adults with visual impairment also remains unexplored. Much more work is required on the development and evaluation of interventions to improve psychosocial well-being in working-age adults with visual impairment. In addition, the inter-relationships of variables require investigation along with causal pathways including the role of personality. 


\section{CONCLUSION}

Working-age adults with visual impairment report lower levels of psychosocial well-being than their sighted peers on measures of mental health, social functioning and quality of life. There was no evidence for the social support network to be reduced and mixed results for the prevalence of depression. Future research is required to document the prevalence of loneliness, clarify the prevalence of anxiety and depression, and test the effectiveness of interventions to improve psychosocial wellbeing directly through counselling/peer support or indirectly through employment programmes using validated and appropriate tools.

Acknowledgements We thank Dr Karen Burnell for her assistance with preliminary work that was submitted to Thomas Pocklington Trust upon which this article is based and who declined an invitation to contribute to this paper. We thank the advisory group for their comments on a summary presentation of the initial findings of this review: Alison Hood (Guide Dogs), lain Hopkin (Thomas Pocklington Trust R\&D Committee), Martin Leyland (Royal Berkshire NHS Foundation Trust, West Berkshire Community Hospital, and Oxford Eye Hospital), Angela McCullagh (Thomas Pocklington Trust), Mary Norowzian (RNIB), and Femi Nzegwu (Guide Dogs).

Funding Thomas Pocklington Trust, 5 Castle Row, Horticultural Place, Chiswick, London W4 4J0.

\section{Competing interests None.}

Contributors Gosney and Victor obtained the grant for this research, Nyman conducted the analysis of the literature for this review and produced the first draft, and all authors contributed to the design of the review and writing of the paper.

Provenance and peer review Not commissioned; externally peer reviewed.

\section{REFERENCES}

1. Royal National Institute of Blind People. Statistics-numbers of people with sight problems by age group in the UK. http://www.rnib.org.uk/xpedio/groups/public/ documents/PublicWebsite/public researchstats.hcsp (accessed 4th May 2008).

2. Resnikoff S, Pascolini D, Etya'ale D, et al. Global data on visual impairment in the year 2002. Bull World Health Organ 2004;82:844-51.

3. Bunce C, Wormald R. Leading causes of certification for blindness and partial sight in England \& Wales. BMC Public Health 2006;6:e58.

4. Bunce C, Wormald R. Causes of blind certifications in England and Wales: April 1999-March 2000. Eye 2008;22:905-11.

5. Boerner K. Adaptation to disability among middle-aged and older adults: the role of assimilative and accommodative coping. J Gerontol B Psychol Sci Soc Sci 2004;59B: P35-42.

6. Altangerel U, Spaeth GL, Rhee DJ. Visual function, disability, and psychological impact of glaucoma. Cur Opin Ophthalmol 2003;14:100-5.

7. Berman K, Brodaty H. Psychosocial effects of age-related macular degeneration. Int Psychogeriatr 2006;18:415-28.

8. Burmedi D, Becker S, Heyl V, et al. Emotional and social consequences of agerelated low vision. Vis Impair Res 2002;4:47-71.

9. Casten RJ, Rovner BW. Psychosocial interventions in age-related macular degeneration. Expert Rev Ophthalmol 2007;2:191-6.

10. Casten RJ, Rovner BW, Tasman WS. Age-related macular degeneration and depression: a review of recent research. Curr Opin Ophthalmol 2004:15:181-3.

11. Heine C, Browning CJ. Communication and psychosocial consequences of sensory loss in older adults: overview and rehabilitation directions. Disabil Rehabil 2002;24:763-73.

12. Horowitz A. Depression and vision and hearing impairments in later life. Generations 2003:27:32-8.

13. Horowitz A. The prevalence and consequences of vision impairment in later life. Top Geriatr Rehabil 2004;20:185-95.

14. Horowitz A, Reinhardt JP. Mental health issues in visual impairment: research in depression, disability, and rehabilitation. In: Silverstone B, Lang M, Rosenthal B, eds. The Lighthouse handbooks on vision impairment and vision rehabilitation. Oxford: Oxford University Press, 2000:1089-109.

15. Mitchell J, Bradley C. Quality of life in age-related macular degeneration: a review of the literature. Health Qual Life Outcomes 2006;4:e97.

16. Slakter JS, Stur M. Quality of life in patients with age-related macular degeneration: impact of the condition and benefits of treatment. Surv Ophthalmol 2005;50:263-73

17. Stelmack J. Quality of life of low-vision patients and outcomes of low-vision rehabilitation. Optom Vis Sci 2001;78:335-42.

18. Berry S, Mangione CM, Lindbald AS, et al. Development of the National Eye Institute refractive error correction quality of life questionnaire: focus groups. Ophthalmology 2003;110:2285-91.
19. Conrad R, Weber NF, Lehnert M, et al. Alexithymia and emotional distress in patients with central serous chorioretinopathy. Psychosomatics 2007:48:489-95

20. Day H, Jutal J, Woolrich W, et al. The stability of impact of assistive devices. Disabil Rehabil 2001:23:400-4.

21. Fok L, Fung HH. Self-concept among people with and without visual impairment: the role of achievement motivation. J Psychol Chin Soc 2004;5:7-24.

22. Garamendi E, Pesudovs K, Elliot DB. Changes in quality of life after laser in situ keratomileusis for myopia. J Cataract Refract Surg 2005;31:1537-43.

23. Hays RD, Mangione CM, Ellwein L, et al. Psychometric properties of the National Eye Institute-Refractive Error Quality of Life Instrument. Ophthalmology 2003;110:2292-301.

24. Margrain TH, Greenland K, Anderson J. Evaluating anxiety in patients attending optometric practice. Ophthalmic Physiol Opt 2003;23:287-93.

25. McDonnel PJ, Mangione CM, Lee $\mathrm{P}$, et al. Responsiveness of the National Eye Institute refractive error quality of life instrument to surgical correction of refractive error. Ophthalmology 2003;110:2302-9.

26. McDonnel PJ, Lee P, Spritzer K, et al. Associations of presbyopia with visiontargeted health-related quality of life. Arch Ophthalmol 2003;121:1577-81.

27. Nichols JJ, Mitchell GL, Zadnik K. The performance of the refractive status and vision profile survey in a contact lens clinical trial. Ophthalmology 2001;108:1160-6.

28. Patel I, Munoz B, Burke AG, et al. Impact of presbyopia on quality of life in a rural African setting. Ophthalmology 2006;113:728-34.

29. Schein OD, Vitale S, Cassard SD, et al. Patient outcomes of refractive surgery: the refractive status and vision profile. J Cataract Refract Surg 2001;27:665-73.

30. Globe DR, Levin S, Chang TS, et al. Validity of the SF-12 Quality of Life Instrument in patients with retinal diseases. Ophthalmology 2002;109:1793-8.

31. Downs SH, Black N. The feasibility of creating a checklist for the assessment of the methodological quality both of randomised and non-randomised studies of health care interventions. J Epidemiol Community Health 1998;52:377-84.

32. Paz SH, Globe DR, Wu J, et al. Relationship between self-reported depression and self-reported visual function in Latinos. Arch Ophthalmol 2003;121:1021-7.

33. Submacular Surgery Trials Research Group. Surgical removal vs observation for subfoveal choroidal neovascularization, either associated with the ocular histoplasmosis syndrome or idiopathic. Arch Ophthalmol 2004;122:1616-28.

34. Varma R, Wu J, Chong K, et al. Impact of severity and bilaterality of visual impairment on health-related quality of life. Ophthalmology 2006;113:1846-53.

35. Donoyama N, Takeda F. Mental health and related factors among massage practitioners with visual impairment. In Health 2007;45:191-8.

36. Janz NK, Wren PA, Lichter PR, et al. Quality of life in newly diagnosed glaucoma patients. Ophthalmology 2001;108:887-98.

37. Cumurcu T, Cumurcu BE, Celikel FC, et al. Depression and anxiety in patients with pseudoexfoliative glaucoma. Gen Hosp Psychiatry 2006;28:509-15.

38. Roy MS, Roy A, Affouf M. Depression is a risk factor for poor glycemic control and retinopathy in African-Americans with type 1 diabetes. Psychosom Med 2007;69:537-42

39. Jampel HD, Frick KD, Janz NK, et al. Depression and mood indicators in newly diagnosed glaucoma patients. Am J Ophthalmol 2007;144:238-44.

40. Collins RL, Taylor SE, Skokan LA. A better world or a shattered vision? Changes in life perspectives following victimization. Soc Cogn 1990:8:263-85.

41. Boerner K, Wang S, Cimarolli VR. The impact of functional loss: nature and implications of life changes. J Loss Trauma 2006;11:265-87.

42. Globe DR, Wu J, Azen SP, et al. The impact of visual impairment on self-reported visual functioning in Latinos. Ophthalmology 2004;111:1141-9.

43. Hahm BJ, Shin YW, Shim EJ, et al. Depression and the vision-related quality of life in patients with retinitis pigmentosa. Br J Ophthalmol 2008;92:650-4.

44. Klein R, Moss SE, Klein BEK, et al. The NEI-VFO-25 in people with long-term type diabetes mellitus. Arch Ophthalmol 2001;119:733-40.

45. Schiffman RM, Jacobsen G, Whittcup SM. Visual functioning and general health status in patients with uveitis. Arch Ophthalmol 2001;119:841-9.

46. Broman AT, Munoz B, West SK, et al. Psychometric properties of the 25-item NElVFO in a Hispanic Population: Proyecto VER. Invest Ophthalmol Vis Sci 2001;42:606-13.

47. Broman AT, Munoz B, Rodriquez J, et al. The impact of visual impairment and eye disease on vision-related quality of life in a Mexican-American population: Proyecto VER. Invest Ophthalmol Vis Sci 2002;43:3393-8.

48. Nirmalan PK, Tielsch JM, Katz J, et al. Relationship between vision impairment and eye disease to vision-specific quality of life and function in rural India: the Aravind comprehensive eye surgery. Invest Ophthalmol Vis Sci 2005;46:2308-12.

49. Janz NK, Wren PA, Lichter PR, et al. The collaborative initial glaucoma treatment study: interim quality of life findings after initial medical or surgical treatment of glaucoma. Ophthalmology 2001;108:1954-65.

50. Leksell JK, Johansson I, Wibell LB, et al. Power and self-perceived health in blind diabetic and nondiabetic individuals. J Adv Nurs 2001;34:511-19.

51. Vu HTV, Keeffe JE, McCarty CA, et al. Impact of unilateral and bilateral vision loss on quality of life. Br J Ophthalmol 2005;89:360-3.

52. Jangra D, Ganesh A, Thackray R, et al. Psychosocial adjustment to visual loss in patients with retinitis pigmentosa. Ophthalmic Genet 2007;28:25-30.

53. Bruce I, Harrow J, Obolenskaya P. Blind and partially sighted people's perceptions of their inclusion by family and friends. Br J Vis Impair 2007:25:68-85.

54. Cimarolli VR, Boerner K. Social support and well-being in adults who are visually impaired. J Vis Impair Blind 2005;99:521-34. 
55. Cimarolli VR, Wang S. Differences in social support among employed and unemployed adults who are visually impaired. J Vis Impair Blind 2006;100:545-56.

56. Cimarolli VR. Perceived overprotection and distress in adults with visual impairment. Rehabil Psychol 2006;51:338-45.

57. Cimarolli VR, Boerner K, Wang S. Life goals in vision rehabilitation: are they addressed and how? J Vis Impair Blind 2006:100:343-52.

58. Boerner K, Cimarolli VR. Optimizing rehabilitation for adults with visual impairment: attention to life goals and their links to well-being. Clin Rehabil 2005;19:790-8.
59. Rimmerman A, Morgenstern H. Quality of life of visually impaired adults who are employed in extended-employment programs in Israel. J Vis Impair Blind 2003;97:551-61.

60. World Health Organization. State of the world's sight VISION 2020: the right to sight: 1999-2005: executive summary. Geneva: World Health Organization, 2005.

61. Horowitz A, Reinhardt JP, Kennedy GJ. Major and subthreshold depression among older adults seeking vision rehabilitation services. Am J Geriatr Psychiatry 2005; 13:180-7. 


\section{Psychosocial impact of visual impairment in working-age adults}

S R Nyman, M A Gosney and C R Victor

Br J Ophthalmol 2010 94: 1427-1431 originally published online October 22, 2009

doi: 10.1136/bjo.2009.164814

Updated information and services can be found at:

http://bjo.bmj.com/content/94/11/1427.full.html

These include:

Data Supplement "Web Only Data"

http://bjo.bmj.com/content/suppl/2010/10/13/bjo.2009.164814.DC1.html

References This article cites 58 articles, 14 of which can be accessed free at: http://bjo.bmj.com/content/94/11/1427.full.html\#ref-list-1

Article cited in:

http://bjo.bmj.com/content/94/11/1427.full.html\#related-urls

Email alerting Receive free email alerts when new articles cite this article. Sign up in service the box at the top right corner of the online article.

Notes

To request permissions go to:

http://group.bmj.com/group/rights-licensing/permissions

To order reprints go to:

http://journals.bmj.com/cgi/reprintform

To subscribe to BMJ go to:

http://group.bmj.com/subscribe/ 